\title{
Anomalias da Diferenciação Sexual: Representações Parentais sobre a Constituição da Identidade de Gênero
}

\author{
Disorders of Sex Development: Parental Representations \\ of Gender Identity Construction
}

\author{
Tatiana Prade Hemesath* \\ Universidade Federal do Rio Grande do Sul, Porto Alegre, Rio Grande do Sul, Brasil
}

\begin{abstract}
Resumo
O estudo investigou as representações de mães e pais sobre a constituição de identidade de gênero em crianças nascidas com diagnóstico de Anomalias da Diferenciação Sexual (ADS). As ADS são distúrbios da diferenciação sexual que resultam em ambiguidade genital na criança. O estudo tem um delineamento qualitativo, com três mães e três pais de crianças nascidas com ADS, de diferentes idades. Utilizou-se a entrevista narrativa e a análise de conteúdo para coleta e análise dos dados. Os resultados mostraram que mães e pais entendem que a identidade de gênero se constitui através da anatomia da genitália, do sexo de criação com o qual a criança é educada e do reconhecimento social que a criança recebe no ambiente em que vive.

Palavras-chave: Anomalias da Diferenciação Sexual (ADS), identidade de gênero, sexo de criação, representação parental.
\end{abstract}

\begin{abstract}
The present study investigated the representations of gender identity construction by mothers and fathers whose children were born with Disorders of Sex Development (DSD). DSD are disorders of sex differentiation which result in ambiguous genitalia in children. A qualitative study with three mothers and three fathers, whose children of different ages were born with DSD, was carried out. Narrative interviews and content analyses were, respectively, the methodological procedures used to collect and analyze the data. Results showed that the criteria mothers and fathers consider as fundamental for the gender identity construction are the genital anatomy, how the child is raised, and the social recognition of the environment where the child lives.

Keywords: Disorders of Sex Development (DSD), gender identity, sex of rearing, parental representation.
\end{abstract}

O distúrbio da diferenciação sexual que resulta em genitália ambígua na criança vem, há muitos anos, se constituindo um problema e um desafio para os profissionais da saúde encarregados de tratar desses casos. Apesar de existirem muitos estudos sobre o tema, abrangendo as mais variadas áreas de interesse, as Anomalias da Diferenciação Sexual (ADS) ainda causam dúvidas e polêmica quanto ao manejo que deve ser empregado no tratamento dessas crianças e no acompanhamento das famílias. A prevalência das ADS é, aproximadamente, de 1:3000 a 1:5000 nascimentos (Bosinski, 2006), sendo fundamental para seu diagnóstico o exame apurado da genitália do recém-nascido, geralmente feito pelo pediatra. A partir do diagnóstico, inicia-se a investigação etiológica, sempre complexa, e esta necessita da atuação integrada de vários especialistas com experiência no tema. A investigação

"Endereço para correspondência: Rua Ramiro Barcelos, 2350, Largo Eduardo Z. Faraco, Porto Alegre, RS, Brasil 90035-903. E-mail: tatihemesath@ig.com.br etiológica culmina na designação sexual da criança e numa proposta de tratamento que inclui geralmente a utilização de tratamento hormonal e a realização de cirurgias, para adequar a aparência e a funcionalidade da genitália (Bosinski, 2006; Damiani \& Steinmetz, 2010; Spinola-Castro, 2010; Telles-Silveira, Tonetto-Fernandes, Schiller, \& Kater, 2009; Zucker, 2006). No entanto, esta conduta, por si só, não soluciona a questão, já que ainda não há um entendimento claro sobre a adaptação psicológica do indivíduo ao sexo designado (Kleinemeier, Jürgensen, Lux, Widenka, \& Thyen, 2010). Isso ocorre porque o sexo designado no nascimento deverá ser "validado" por um conjunto de características orgânicas e psicológicas, como por exemplo, a capacidade dos pais para criarem o filho consonante ao sexo designado e, mais além, a identidade e o papel de gênero do indivíduo nascido com ADS, resultante da organização dos diferentes níveis de distinção sexual: genético, nuclear, gonadal, fenotípico e psicossocial (Santos \& Araújo, 2003).

Santos e Araújo (2003) ressaltam a importância de discutir a construção psicossocial do portador de ADS, 
uma vez que é esta que determinará a adequação (ou não) entre a identidade sexual (sexo biológico) e a identidade de gênero (sentimento do indivíduo de pertencer ao sexo masculino ou feminino). O papel dos pais nessa construção é fundamental, pois são os responsáveis pelas primeiras relações da criança com o mundo externo e "imprimem" na mesma suas representações acerca de sua identidade sexual, e da subsequente articulação entre esta e a identidade de gênero.

Stoller (1993) coloca que sexo é a qualidade de ser homem ou mulher, e que este aspecto está ligado ao estado biológico do indivíduo (cromossomas, genitais externos, gônodas, aparatos sexuais internos, estado hormonal, características sexuais secundárias e cérebro). Já a identidade de gênero é um estado psicológico e diz respeito à masculinidade e feminilidade. Sexo e gênero não estão necessariamente relacionados. Assim, as experiências pós-natais podem modificar, ou até mesmo sobrepujar, tendências biológicas já presentes.

Masculinidade ou feminilidade são definidas por Stoller (1993) como uma "soma algébrica" de uma massa densa de conviç̧ões que levam o indivíduo a se sentir pertencendo qualitativamente a um ou outro sexo. Neste sentido, a identificação com o sexo biológico implica num processo conflitivo originado primordialmente pela oposição do que é masculino e feminino.

A resolução dos conflitos e o estabelecimento de identificações saudáveis com as figuras parentais são aspectos importantes na constituição da identidade de gênero do sujeito. Assim, adquirem importância as atitudes dos pais no processo identificatório por que toda a criança passa, sendo a identificação com uma das figuras parentais essencial para o desenvolvimento adequado da identidade de gênero (Freud, 1905/1996b).

Nesta linha de pensamento, Stoller (1993) afirma que uma das bases da constituição da identidade de gênero é, entre outros fatores, a combinação da designação do sexo no nascimento do bebê com a posterior influência das atitudes dos pais sobre o sexo daquele bebê. A primeira traria uma espécie de "mensagem" sobre a aparência dos genitais externos do bebê, que impulsionaria uma gama de efeitos inequívocos subsequentes a esta designação para convencer os pais sobre o sexo da criança. Isto garantiria uma primeira imagem com impacto mnêmico (consciente e inconsciente), produzida para representar o filho que os pais têm ali. A partir disso, os pais lançam mão de uma série de atitudes, que serão diferentes se a criança é do sexo masculino ou feminino, e essas serão progressivamente interpretadas pela criança como acontecimentos, ou seja, experiências motivadas e significativas. Diante de um bebê com ADS, porém, esse processo fica obstaculizado, gerando grande confusão e ansiedade nos pais num primeiro momento e para a criança, posteriormente.

A questão da identidade sexual em pacientes com diagnóstico de ADS foge aos padrões normais estabelecidos na literatura sobre o tema, pois anatomicamente estes pacientes não possuem identidade sexual estabelecida no nascimento. Esta apenas será definida após a investigação etiológica da doença, mediante achados clínicos baseados em exames e sendo mediada pelas expectativas dos pais. Os pais, portanto, encontram-se totalmente envolvidos no problema, apresentando sentimentos diversos e adquirindo, pouco a pouco, suas próprias representações acerca da ADS, baseadas no que escutam dos profissionais envolvidos no tratamento, dos familiares e de outras instâncias do contexto cultural.

Apesar da maioria dos autores (Nihoul-Fékété, 2008; Santos \& Araújo, 2004; Spinola-Castro, 2010; Stoller, 1993; Telles-Silveira et al., 2009; Zucker, 2006) entenderem que os pais são fundamentais para o desenvolvimento das crianças com ADS, há poucos estudos que têm investigado as suas representações sobre esta condição. No presente estudo, buscou-se escutar os pais para tentar compreender como eles representam os elementos subjacentes à identidade de gênero do filho com ambiguidade genital, em meio a sua exposição aos vários discursos, da equipe médica e daquele que provém de seu ambiente sociocultural. A expectativa inicial era de que nas narrativas que seriam construídas pelos pais emergiriam suas representações sobre a identidade de gênero de seus filhos com ADS.

\section{Método}

\section{Participantes}

Os pais foram convidados pela pesquisadora a participarem do estudo por ocasião de seu comparecimento à consulta de revisão da criança, em um ambulatório de Cirurgia Pediátrica de um hospital universitário do sul do país. O número de participantes no estudo foi definido com base nas possibilidades de que dispõe este ambulatório e, posteriormente, dependeu do aceite dos pais para a participação na pesquisa, sendo que todos que aceitaram participar assinaram o Termo de Consentimento Livre e Esclarecido. ${ }^{1}$ Foram entrevistados 6 mães e 5 pais de crianças com diagnóstico de ADS, de diferentes etiologias, com idades entre 0 e 12 anos. Dessas 11 entrevistas realizadas, foram selecionadas 3 entrevistas com as mães (de crianças de 0,4 e 12 anos de idade) e 3 entrevistas com os pais (de crianças com 0,3 e 4 anos de idade), sem a necessidade dos entrevistados constituírem casais. Todas as crianças recebiam acompanhamento sistemático no referido ambulatório do hospital, tendo consultas junto à Cirurgia Pediátrica em frequência trimestral. A escolha das entrevistas foi feita com base na disponibilidade dos pais para relatarem a situação que enfrentavam de maneira detalhada, oportunizando assim uma ampla coleta de informações. A diversidade das idades das crianças foi contemplada para permitir o estabelecimento de comparações entre os resultados provenientes das narrativas de mães e pais de crianças que estão em diferentes etapas do desenvolvimento e tratamento da ADS. A Tabela 1

\footnotetext{
${ }^{1} \mathrm{O}$ projeto de pesquisa foi avaliado e aprovado pelo Comitê de Ética em Pesquisa do Hospital de Clínicas de Porto Alegre (projeto ${ }^{\circ}$ 08-596).
} 
Hemesath, T. P. (2013). Anomalias da Diferenciação Sexual: Representações Parentais sobre a Constituição da Identidade de Gênero.

apresenta o ordenamento das mães e pais entrevistados, as respectivas idades dos pacientes no momento em que a coleta de dados foi realizada, se já realizaram alguma cirurgia e a etapa do tratamento em que se encontram.

Tabela 1

Ordenamento das Mães e dos Pais Entrevistados

\begin{tabular}{lccc}
\hline Mãe/Pai & Idades das crianças & Cirurgias realizadas & Etapa do tratamento \\
\hline M1 & 12 anos & 3 & Planejamento da próxima cirurgia \\
M2 & 1 mês & 0 & Investigação etiológica em fase final \\
M3 & 4 anos & 6 & Planejamento da próxima cirurgia \\
P1 & 3 anos & 3 & Acompanhamento \\
P2 & 4 anos & 1 & Acompanhamento \\
P3 & 2 meses & 0 & Investigação etiológica concluída \\
\hline
\end{tabular}

\section{Delineamento, Procedimentos e Instrumentos}

Foi utilizado um delineamento de casos múltiplos, sendo cada caso uma unidade de análise. Utilizou-se a entrevista narrativa (cf. Bauer \& Jovchelovitch, 1999) com o objetivo de incentivar os pais a falarem sobre o que sentem e pensam a respeito da condição de ADS dos filhos, na forma de narrativa. Colocou-se a seguinte questão aos pais: "Eu gostaria que tu me contasses uma história sobre a situação de teu(tua) filho(a) ter nascido sem o sexo definido", para incentivá-los a narrar a(s) história(s) relacionada(s) à situação de ter um filho portador de ADS. As entrevistas foram realizadas entre maio e outubro de 2009. Os pacientes foram identificados através dos médicos da equipe e na data agendada para a consulta foi realizada a entrevista narrativa pela autora ${ }^{2}$ individualmente, com cada um dos pais. As entrevistas tiveram uma duração média de 50 minutos, sendo as narrativas produzidas pelos pais gravadas digitalmente e depois transcritas.

A Análise de Conteúdo Temática (Bardin, 1977/2009) foi utilizada para examinar as representações de mães e pais de crianças com ADS acerca da constituição da identidade de gênero das mesmas. ${ }^{3}$ Após a leitura extensiva do material, foi realizado um recorte de conteúdos em função de sua significação para o estudo. Durante as análises, deu-se importância tanto às particularidades quanto às semelhanças entre os casos, uma vez que as crianças se encontravam em diferentes etapas de vida e do tratamento.

\section{Resultados e Discussão}

Das narrativas das mães, mais extensas do que as dos pais, emergiram quatro categorias temáticas referentes

\footnotetext{
${ }^{2}$ A autora é psicóloga contratada do Hospital de Clínicas de Porto Alegre, onde pratica assistência aos pacientes com diagnóstico de ADS e seus pais, ao longo das várias etapas de seu tratamento.

${ }^{3} \mathrm{O}$ presente estudo deriva da dissertação de mestrado da autora, na qual uma série de outros aspectos que emergiram das narrativas das mães e dos pais entrevistados foram discutidos. Neste artigo, apenas as representações acerca da identidade de gênero, oriundas das narrativas, são apresentadas.
}

às suas percepções sobre a constituição da identidade de gênero dos filhos: percepção sobre a anatomia da genitália, identidade da criança vinculada à identidade sexual, escolha do sexo de criação, funcionalidade sexual. Das narrativas dos pais originaram-se três categorias temáticas: percepções acerca da identidade de gênero, escolha do sexo de criação, funcionalidade sexual. Recortes retirados das entrevistas ilustram as categorias.

\section{As Representações das Mães sobre a Constituição da Identidade de Gênero}

Percepção sobre a Anatomia da Genitália. As narrativas das mães evidenciaram a importância atribuída por elas à anatomia da genitália da criança, ambígua ao nascimento, para o entendimento da identidade sexual de seus filhos, o que influencia as representações que constroem sobre esta identidade. Esta situação mobiliza angústia em função da discriminação que temem que o filho possa sofrer no ambiente social em que vive:

... e como eu trabalho, eu tive que me precaver. Então fui falar com as cuidadoras da escolinha ... porque elas vão ver, porque é visivel... tem que explicar o problema, porque é diferente dos outros meninos. Agora ainda mais porque está aberto. Ele tem um formato dum penizinho, mas ele é todo aberto em baixo, né. Tu olha e parece uma ... uma... a parte dos grandes lábios de uma vagina, né... é muito complicado. (M3)

Duas das mães (M1 e M3) referiram o fato das diferenças anatômicas entre os sexos (masculino e feminino) serem aprendidas desde cedo pelas crianças: "Ele logo percebeu, quando foi para a escola, né... que ele era o único menino a fazer xixi sentado..." (M1).

. . é importante para a criança conhecer o corpo, né... e a gente fala para ele sobre o pinto né... e eles, se a gente não fala, ficam muito sem conhecer a menina também, né... eu tomo banho com ele, o pai dele também toma banho com ele... isso faz com que ele entenda o corpo das pessoas, e as diferenças entre os corpos masculino e feminino, com muito mais naturalidade. (M3) 
Os recortes mostram que as mães consideram necessário aprender sobre a diferença entre os dois sexos, pois isto ajudaria a criança a apropriar-se dessa diferença e, posteriormente, do sentimento de pertencimento a um ou outro sexo. Além disso, as mães atribuem à aparência da genitália a causa do sucesso ou fracasso das relações sexuais futuras do filho. Portanto, temem que uma genitália esteticamente "incorreta" possa comprometer tanto a funcionalidade sexual como constranger os filhos. Esta preocupação inicia usualmente mais tarde, quando a criança já apresenta desenvolvimento físico e emocional maior. Intensifica-se, porém, na adolescência. Observa-se isso nas verbalizações de uma das mães (M1), com filho nesta fase:

e aí, às vezes, eu fico assim, meio apreensiva, não sei se ele quando crescer mais, quando tiver uma namorada... se não vai se achar feio... na frente da menina... tenho medo de que fique constrangido com o pênis dele... (M1)

Identidade da Criança Vinculada à Identidade Sexual. Esta categoria relaciona-se à identidade sexual da criança (menino ou menina), um dos aspectos que compõem a identidade subjetiva e posterior identidade de gênero. A fala de uma das mães cuja filha encontrava-se em etapa final da investigação etiológica, já com a designação sexual ilustra este aspecto, mostrando a insegurança da mãe quanto à designação sexual realizada:

. . . ah, não sei... se no final disso tudo tivesse uma garantia, não [se criassem a filha sem situá-la no sexo masculino ou feminino $]^{4}$... é que ia complicar muito, né... como é que ia ficar a cabeça da criança? Ela não ia saber quem ela era, se ela era menino ou menina, ia ser dificil para ela [ficar sem identidade]. (M2)

A verbalização da mãe (M2) evidencia que o sexo da criança é um aspecto prioritário na formação da identidade subjetiva da criança. As mães já escolhem nomes para seus filhos antes mesmo deles nascerem. O impacto é grande quando elas recebem o diagnóstico de ADS e a orientação médica de que devem esperar pela investigação etiológica para registrar o filho:

Aí ontem ela [pediatra] me perguntou, né... ah, o que eu ia achar se a decisão era se fosse menino. Ai eu falei 'ah, eu ia sentir que a (nome da filha) teria morrido... eu teria perdido a (nome da filha)... no caso, eu teria ganho um filho, mas aquela criança que estava ali comigo, teria perdido... (M2)

A verbalização mostra que as mães têm sentimentos de angústia e confusão durante o período em que esperam para que sejam "autorizadas" pela equipe médica a atribuir uma identidade - que se inicia com a definição da identidade sexual e com a legitimação desta através de um nome - ao filho. Quando o(a) filho(a) é maior, as questões de identidade começam a se sedimentar, diminuem as dúvidas

\footnotetext{
${ }^{4}$ Nomes próprios, de cidades ou hospitais serão substituídos pela definição entre parênteses, a fim de preservar o sigilo dos entrevistados. Trechos das verbalizações onde não ficar explícito o que o entrevistado quer dizer, serão complementados por explicação ou a palavra entre colchetes.
}

relativas à designação sexual inicial, como mostrado a seguir "Quanto a ter dúvida assim se, ah, se ele tem alguma coisa feminina, não ... mas quanto a isso, tudo bem... hoje em dia não me resta dúvida nenhuma..."(M1)

Escolha do Sexo de Criação. Três mães (M1, M2 e M3) enquadram-se nesta categoria relacionada à identidade sexual (menino ou menina). Pais e mães usam esta identidade como parâmetro para educar seus filhos com ADS e escolher roupas, brinquedos e estratégias de criação. Para as mães, o sexo designado deve ser por elas sustentado, ao longo do desenvolvimento da criança. Em suas verbalizações, nota-se que usam estratégias educativas, baseadas na cultura relacionada aos dois sexos, para firmar a identidade de gênero já iniciada com a designação sexual:

...já desde pequinininho, todos trataram como se fosse mesmo um menino... quando ele começou a caminhar, o pai dele, né... e meu cunhado... começaram a jogar futebol com ele, a dar brinquedos, né... porque todo ser humano, né, exige que a gente encaminhe... então tu é quem dirige, né... nas meninas a gente coloca vestidinho, lacinho... se a gente vê uma menina de calção, camiseta e tênis fica estranho, né... a gente já acha que está faltando alguma coisa, né... isso é automático...toda a desenvoltura da criança começa quando ela começa a se conhecer, né... então isso é importante... (M3)

O processo de identificação do filho com o genitor do mesmo sexo é outro aspecto levantado pelas mães (M1 e M3). Em suas falas observa-se que este é visto como bastante similar ao processo normal de identificação, inerente ao desenvolvimento psicossocial de qualquer criança: " $n \tilde{a} o$ tenho dúvidas... os pais vão sendo modelos, né..." (M3).

O sexo de criação é considerado como um forte catalisador na construção da identidade de gênero dos filhos com ADS, podendo notar-se isto nas falas das mães. Elas o entendem como uma possibilidade de contribuição delas aos filhos, pois, através dele, elas saem da posição de passividade em que se percebem por ocasião do diagnóstico médico e da proposta de tratamento hormonal e cirúrgico. A postura assumida na ação cotidiana de educar o filho conforme o sexo designado traz alívio e legitima progressivamente a identidade sexual que a criança recebeu da equipe médica:

Saber dos médicos que ele seria um menino, mudou todo meu mundo... estava com enxoval pronto e tudo... porque eu tinha feito a eco na gravidez e mostrou que era uma menina. Mas depois que eu levei ele para casa e ficava vendo o rostinho dele... ããăh, foi ficando mais fácil olhar ele como um menino mesmo. E fui criando ele assim então... (M1)

Funcionalidade Sexual. Esta categoria envolve as preocupações das mães referentes à função e desempenho sexual dos filhos na maturidade, e se expressa nas narrativas de três delas (M1, M2 e M3). Apesar de serem mães de filhos de diferentes idades, elas se mostraram atemorizadas com a adaptação futura de seus filhos em questões inerentes à vida adulta. A questão da satisfação sexual do filho gera dúvidas, mas também a de que o desenvolvimento do órgão 
sexual adeque-se às necessidades do parceiro no futuro. $\mathrm{O}$ recorte a seguir ilustra este ponto:

Receio que vá ficar muito defeituoso [o pênis], né, que vá constranger ele com as meninas... mas eu espero que não... segundo eles [os médicos] não, porque tem uma plástica reparadora... e provavelmente vai ficar bem mais perto do que deve ser... então eu vou estar aguardando... (M3)

Outra mãe (M2) manifesta preocupação quanto à capacidade de sua filha tornar-se uma mulher "perfeita":

Agora ela é só um bebê... mas sexo étudo nesse mundo, atualmente... e será que mais tarde ela vai conseguir ser uma mulher completa? Será que ela terá um corpo de mulher, assim como tem que ser... será que vai conquistar um homem e ele vai gostar de como ela vai ser? (M2)

A preocupação com a capacidade reprodutiva do filho com ADS também aparece nas falas das mães (M1 e M3), com relação à possibilidade de exercer ou não a maternidade ou paternidade no futuro: "Eu perguntei para o médico e o médico disse que não... que é normal isso aí, que vai continuar [a se desenvolver o pênis]... e ter filhos também, né..." (M1)

A característica crônica da doença impede que o futuro dos filhos e o prognóstico e resultado do tratamento, no qual investem por todo o percurso do desenvolvimento da criança e do adolescente, possam ser visualizados precocemente, gerando angústia:

E quanto a... a... o que eu quero saber também é quanto a, no futuro, se ele vai poder ser reprodutor normal, se vai ter filhos... isso aí já não... não foi dito assim... porque até eu sei que isso não vai ser agora... ele vai ser acompanhado tanto pela urologia como pela endocrinologia até a adolescência... até ele parar de crescer, né... (M3)

E a ausência de garantias em relação a vários aspectos do desenvolvimento da criança com ADS gera não apenas dúvidas e confusões, mas fantasias distantes da realidade trazida pelo prognóstico da doença. A esperança das mães de que seus filhos se desenvolvam dentro da normalidade, atendendo aos preceitos socioculturais vigentes, aparece no discurso das três mães entrevistadas (M1, M2 e M3). A realidade da doença e do tratamento colide com essas expectativas, mudando o percurso idealizado para seus filhos.

Nas verbalizações das mães, as questões da funcionalidade sexual articulam-se com as questões da identidade de gênero futura dos filhos. As características que a criança incorpora, e que cada vez mais expressam que pertencem a um dos sexos (masculino ou feminino), vão progressivamente trazendo alívio às mães. Entram, então, em contato com uma identidade de gênero mais definida da criança, mas que só será efetivamente consolidada, na opinião delas, quando o meio social reconhecer essas características como genuinamente ligadas ao sexo masculino ou feminino. Assim, não só o tratamento e seus resultados futuros angustiam pelas incertezas, mas também o futuro homem ou a futura mulher (ainda não assegurados) que o filho pode vir a ser ou não.
As Representações dos Pais Homens

sobre a Constituição da Identidade de Gênero

Percepção acerca da Identidade de Gênero. A categoria diz respeito às percepções que os pais homens têm das questões sobre a identidade de gênero do filho com ADS. Inclui as verbalizações de dois dos pais (P1 e P2), cujos filhos já são maiores (Tabela 1). Ambos os pais entendem que seus filhos já têm identidade de gênero constituída e que a mesma pode ser percebida pelo meio externo. A verbalização do pai (P1) ilustra este aspecto: "Ele adora olhar o tico dele... aquela coisa é pequena ainda, mas enche ele de orgulho... parece mentira... é diferente do meu e muito diferente do do irmão dele, mas para ele não importa..." (P1).

Um dos pais verbalizou receio diante da preferência esportiva da filha, que não lhe parecia adequada para uma menina. Será que a identidade de gênero da filha poderia ser mensurada através desse marcador? Preocupava-se com o significado do esporte para ela e de como isso poderia ser julgado pelo meio externo: "Esses dias tava aí, ó, jogando bola ... ai meu Deus!" (P2).

As falas que fazem parte desta categoria indicam que os pais homens têm representações fantasiosas acerca da identidade de gênero de seus filhos, como se essa identidade estivesse sobre uma estrutura frágil, podendo deteriorar-se ou modificar-se com facilidade. Há o temor de que a definição da identidade de gênero, construída a partir da escolha do sexo de criação, possa gerar apenas um falso invólucro que ocultaria em seu interior um sentimento de pertencer ao outro sexo que não o designado inicialmente. Essa característica mutável que os pais homens fantasiam sobre a identidade de gênero está ligada às transformações que a genitália pode sofrer ao longo do desenvolvimento. Um dos pais, ao falar do tratamento hormonal que a filha deve receber ininterruptamente e em doses extremamente controladas, mostra o temor de que se isso não for cumprido, seu corpo (e consequentemente, seu comportamento) possa assumir características anatomicamente masculinas (virilização, crescimento de um falus):

... eu quero que ela seja feliz. O que ela decidir ser, o que quiser ser, que se sinta no direito, que vai ter todo o meu apoio... não adianta querer dar algum... como se diz... um outro hormônio, né... se parar de tomar remédio, vem o hormônio masculino e sobe... pára o feminino, né... pode crescer o pênis, aquelas coisas. Mas se fosse masculino mesmo, e se decidir ser outra coisa, dai não... eu não vou ir contra. A gente fica, né, dando o tempo necessário, para que seja bonita, para que apareça o útero, né... mas o medo é que seja só uma capa, né [o gênero feminino] ... que não saia muito certo... mas ela sempre foi criada como guria, né. Mas vai que numa altura, numa nuvem de pensamento, né... se quiser mudar, vai ser apoiada nessa decisão... (P2)

Para os pais homens, a identidade de gênero da criança constrói-se a partir de modelos paternos, com base na comparação da anatomia genital entre as crianças e seus respectivos pais e na reprodução de hábitos cotidianos de conotação ativa (masculina) ou passiva (feminina). Este 
aspecto ficaria evidente ao se observar o sofrimento emocional da criança por não conseguir urinar em pé como seu pai costuma fazer:

Até em casa, a gente pega ele e coloca ele sentadinho no vaso para urinar, eu vou no banheiro e ele vai junto e vê eu urinar de pé... ele fica olhando, fala "é um tico" e coisa e tal, tu vê que ele já esta percebendo que ele faz a coisa diferente. Bah, "o pai faz assim, porque que eu tenho que fazer sentado?". Eu fico pensando como vou tratar quando ele pedir para fazer de pé. (P1)

Escolha do Sexo de Criação. Esta categoria temática sobre a escolha do sexo de criação também é pelos pais homens associada à constituição da identidade de gênero. Embora refiram que a identidade de gênero de seus filhos com ADS pode ser mais frágil e lábil do que a de uma criança com desenvolvimento normal, são categóricos quando falam sobre a escolha do sexo de criação para seus filhos (P1 e P2), afirmando que não há como educar uma criança sem definir o sexo da mesma. A verbalização a seguir mostra isso:

Não tem como dizer, assim, como tu vai criar uma pessoa assim, um ser humano se tu não sabe se é menino ou menina, não tem como, é dificil, mas a gente conseguiu definir é homem é homem, vamos tratar como homem. (P1)

Apesar dos pais ( $\mathrm{P} 1$ e P2) indicarem que entendem que o sexo de criação é um fator fundamental para a educação da criança e para o desenvolvimento das estratégias parentais para lidar com a mesma, parece a eles ser insuficiente para a consolidação de uma identidade de gênero saudável. Olham, então, o futuro dos filhos na posição de expectadores, esperando a ocorrência de um transtorno de identidade de gênero decorrente de fatores biológicos.

Funcionalidade Sexual. As verbalizações dos pais homens nesta categoria dizem respeito à angústia que experimentam diante do tratamento das ADS, ou seja, da incerteza relativa aos resultados futuros do tratamento. Os questionamentos que os pais (P1, P2 e P3) fazem quanto a esses resultados ligam-se a aspectos de identidade de gênero dos filhos, à funcionalidade sexual futura, à capacidade reprodutiva, entre outros. A fala de um pai (P2), que entende que os resultados da evolução hormonal inerentes à etiologia da ADS de sua filha podem causar mais tarde um comprometimento na identidade de gênero da mesma, ilustra este questionamento:

Bom, a gente hoje em dia vê tanta gente que tem direito de escolher... que fique bem claro, gays e lésbicas, talvez não tenham nada daquilo que minha filha teve [aumento carga hormonal masculina em função do tipo de ADS], mas eu quero dizer assim, que não tem nada de hormônio, né... eu acredito que não tem. Tem algumas pessoas que é por livre escolha [a conduta sexual] ... mas como ela já tem, né...se parar de tomar [o hormônio feminino] aquilo ali já volta o corpo dela a se manifestar de outras formas [virilização]... (P2)

A ênfase dada ao meio social como um balizador da identidade de gênero da criança é outro aspecto importante que aparece nas narrativas dos pais. Estes (P1, P2 e P3) temem que a criança fique exposta, primeiro, aos colegas da escola e outros cuidadores e, posteriormente, frente aos parceiros sexuais, sofrendo rechaço ou sendo desvalorizada como ser humano.

Meu medo é daqui para frente, porque agora ele está na escolinha, dai tem o particular dele na hora de fazer as necessidades. Mas quando ele for para a escola mesmo, primeira série, segundo ano, sei lá, dai vai usar um banheiro público... vai estar sempre fazendo cocô [porque não consegue urinar em pé, tem que ser sentado] ... se não corrigir isso, não tem como ele chegar no mictório e urinar ali, é isso que eu penso. (P1) O pai mostra temor de que o filho possa ser visto pelo meio social (num banheiro público, por exemplo) tendo uma conduta culturalmente compreendida como pertencendo ao sexo feminino (urinar sentado).

Já outro pai (P2) refere-se ao futuro sexual da filha como preocupante e cercado por desafios. Nota-se isto quando fala da chegada da filha à maturidade sexual, quando se interessar em ter um parceiro e filhos: " $E$ o dia que quiser namorar? E o dia que quiser ter filhos? Como é que vai ficar a cabeça dela e a nossa junto, né? Porque dai vai ser o dobro, né, vai ser só preocupação..." (P2).

As dúvidas dos pais homens sobre o desempenho sexual dos filhos no futuro e se os mesmos obterão satisfação sexual em suas relações apareceram também em suas narrativas (P1, P2 e P3): "Outra questão que eu queria fazer é se ela vai ter prazer normal, entendeu?" (P3).

Só penso no futuro dele... se a gente não corrigir isso aí até uns 6, 7 anos... dai vai começar a complicar. Essa é a única dificuldade que eu vejo, porque o resto eu acho que... porque ele tem ereção, tem tudo, acho que a vida sexual dele não vai ser atingida, acredito eu. Sei lá como vai ficar, mas a gente acha que não prejudica em nada. (P1)

Como esperado, as narrativas dos pais homens e das mães revelaram suas representações sobre a identidade de gênero de seus filhos com ADS. No geral, através delas expressaram preocupações com o futuro de seus filhos e que estas não podem ser resolvidas durante a infância, acompanhando tanto a eles quanto a seus pais durante muito tempo. A preocupação de ambos, mães e pais, com o desempenho sexual futuro de seus filhos mostra que se mantêm atentos com relação à coerência entre a identidade de gênero já consolidada (ou não) e a identidade sexual definida precocemente.

\section{Conclusão}

Os resultados do presente estudo mostram que ambos os pais atribuem importância à anatomia da genitália da criança, considerando-a como um fator que marca a identidade sexual da mesma e sobre a qual se constrói a identidade de gênero futura. Para além da ambiguidade genital do filho ao nascer, o que pôde ser observado é que há consenso por parte dos pais quanto à impossibilidade da criança desenvolver uma identidade de gênero saudável sem a definição de uma identidade sexual prévia. 
Freud (1925/1996a), apesar de nunca ter feito referência às identidades sexual e de gênero, ao descrever e conceituar os processos identificatórios, trouxe elementos importantes para a compreensão da identificação do ser humano com o sexo masculino ou feminino. Nos primórdios de seus estudos sobre o desenvolvimento sexual da criança, atribuía um importante valor para o corpo principalmente no que dizia respeito à sua anatomia genital. Freud afirmava que a diferença entre o desenvolvimento sexual dos indivíduos dos sexos masculino e feminino é uma consequência inteligível da distinção anatômica entre seus órgãos genitais e da situação psíquica que está envolvida nisto. Ou seja, para Freud, a repercussão psíquica gerada a partir do reconhecimento de anatomias genitais diferentes é fundamental para a organização das identidades masculina e feminina que cada indivíduo desenvolverá. Isto repercutirá posteriormente na subjetividade, quando esta primeira representação das crianças se tornará responsável por suas organizações egóicas. Neste estudo, fica claro que a designação sexual, que se segue à adequação cirúrgica da genitália, é para os pais um aspecto organizador da futura identidade de gênero da criança.

Embora o primeiro impacto causado pela ambiguidade genital no nascimento de um bebê com ADS gere representações ambivalentes em ambos os pais, estes parecem abandonar a imagem do filho "com dois sexos" após a designação sexual e o consequente registro do bebê. Estes fatores tornam possível a emergência de uma identidade subjetiva da criança. É sobre a designação sexual, realizada após extensa investigação clínica da etiologia da ADS, de acordo com o que é preconizado em grandes centros de referência que tratam destes pacientes, que se constitui a identidade de gênero para os pais que participaram deste estudo. A designação sexual do bebê, de acordo com os pais entrevistados, os auxilia a perceber o(a) filho(a) como pertencendo a um único sexo, quer seja masculino ou feminino.

Outra semelhança que se faz presente nas narrativas dos pais diz respeito a como o meio social visualiza essa anatomia considerada imperfeita desde o nascimento. Ambos os pais temem que o filho seja discriminado no ambiente social em que está inserido, em razão da anatomia genital diferenciada ao nascimento, o que lhes traz angústia. Em função disso, eles entendem como válido todo suporte médico/tecnológico que possam receber para garantir a adequação do(a) filho(a) ao sexo designado.

Para além da medicina, no entanto, os pais consideram que o que poderia compensar socialmente a "imperfeição" anatômica genital seria a criança ter uma conduta coerente com sexo designado pelos médicos. Os pais deste estudo entendem que esta conduta seria decorrente do sexo de criação com o qual educam seus filhos. Todas as três mães (M1, M2 e M3) e dois dos pais (P1 e P2) atribuem valor considerável à escolha do sexo de criação, entendendo-o como uma estratégia de relacionamento com a criança capaz de promover o desenvolvimento saudável e formar um indivíduo com maiores chances de adaptação futura. Consideram também que os filhos desenvolvem uma identidade de gênero consonante com a identidade sexual, mediante os modelos maternos e paternos de que dispõem. No estudo de Santos e Araujo (2004), o desenvolvimento da identidade de gênero em crianças com ADS foi investigado através dos significados atribuídos por elas à sua condição. Os resultados mostraram que as características de maleabilidade ou flexibilidade do sujeito em desenvolvimento, quando discutidas em relação à sua condição de ADS, estavam associadas tanto ao modo de criação (com maior flexibilidade ou maior rigidez e cobrança em relação à identidade e papel de gênero) quanto às etapas próprias do desenvolvimento.

Assim, os resultados deste estudo vêm ao encontro daqueles encontrados por um número expressivo de autores (Kleinemeier et al., 2010; Money \& Ehrhardt, 1972; Money, Hampson, \& Hampson, 1957; Santos \& Araújo, 2003, 2004; Slijper et al., 1992; Telles-Silveira et al., 2009; Zucker, 2006). Como já assinalado, boa parte da literatura na área mostra que ambos os pais definem o sexo de criação mediante a designação sexual da criança com ADS, tendo como principal pressuposto a anatomia da genitália (aparência adequada ao sexo designado). A partir desse critério, seguem os marcadores sociais tradicionais (escolhas de roupas, brinquedos, cores, que identificam a criança como pertencendo ao sexo masculino ou feminino), e acreditam que é importante sua atuação como modelo de identificação para os filhos do mesmo sexo. Neste estudo, os pais de crianças com situação de ADS estereotipam, igual aos pais de crianças sem situação de ADS, tanto a qualidade da relação com filhos meninas e meninos quanto as escolhas de brinquedos, roupas e atividades em geral. Os pais entrevistados consideram o sexo de criação uma poderosa estratégia para a constituição de um indivíduo bem adaptado ao sexo designado, embora entendam que apenas isto, isoladamente, não é suficiente para desenvolver uma identidade de gênero que seja consonante com a identidade sexual definida.

Há, no entanto, algumas características nas respostas de pais homens deste estudo a considerar (P1, P2 e P3). As narrativas desses pais, de uma forma sutil, indicaram que se sentem ambivalentes quanto à designação sexual dos filhos. Por exemplo, são unânimes ao dizer da importância em criar seus filhos dentro da designação sexual recebida, após o término da investigação etiológica. Entretanto, pensam na possibilidade de mais tarde, na vida adulta, os filhos virem a ter interesse por pessoas do mesmo sexo, o que caracterizaria uma escolha homossexual. Este aspecto confunde-se no pensamento dos pais homens com a questão da identidade de gênero: eles não abordam o assunto como um transtorno de identidade de gênero, o que seria o esperado diante de uma designação sexual não aceita pelo indivíduo com ADS, quando da chegada à adultez. Esta confusão feita pelos pais homens, assemelhando os conceitos de escolha sexual e identidade de gênero, e a percepção ambivalente relativa ao/à filho(a), pode interferir nas práticas parentais adotadas por eles, relativas ao sexo de criação. Zucker (2006), em seus estudos envolvendo adolescentes nascidos com ADS, percebeu que quando 
esses adolescentes apresentam comportamentos contrários aos esperados diante do sexo designado (ex: comportamento masculino em meninas), normalmente apresentam um aspecto em comum: foram criados em ambientes ambivalentes, com pais que não aceitaram a recomendação médica de criar o filho em consonância com o sexo designado. Os adolescentes em questão desenvolveram-se em ambientes familiares marcados por incertezas, ambivalências e ceticismo.

Diante do que foi discutido, pode-se perguntar: como os pais neste estudo representam a identidade de gênero de seus filhos nascidos com ADS? Há três pontos que se mostraram importantes para a construção desta representação:

1. A configuração anatômica da genitália do filho e como esta responde pós-cirurgicamente ao sexo designado, de forma a validar um ou outro sexo (menino ou menina);

2. O sexo de criação escolhido pelos pais, caracterizando estratégias parentais, opções de roupas e brinquedos que definem a criança como pertencendo a um ou outro sexo definido; e

3. O reconhecimento social que a criança irá receber como pertencendo a uma comunidade masculina ou feminina. Neste estudo, os pais reconhecem que a identidade de gênero dá-se através desses três níveis de "validação" da identidade sexual da criança, embora atribuam importância fundamental aos modelos de identificação dos quais são os responsáveis maiores. Porém, esse fator, chamado aqui de sexo de criação, somente será por eles definido a partir da visualização da anatomia genital definidamente masculina ou feminina. Ela constitui-se para os pais deste estudo como o primeiro organizador da identidade de gênero da criança com ADS.

Devido à pequena amostra de casos que fizeram parte do estudo, os resultados não podem ser considerados como aplicáveis a outras amostras ou contextos. Outras características que não foram abordadas nesta investigação tais como os referenciais maternos e paternos acerca de gênero e as especificidades de pais/mães de meninas e meninos sobre a constituição da identidade de gênero de seus filhos, poderiam trazer subsídios complementares para uma maior compreensão clínica do quadro de ADS. Pesquisas envolvendo adolescentes nascidos com ADS e sua própria percepção sobre a constituição da identidade de gênero, também deveriam ser desenvolvidas.

\section{Referências}

Bardin, L. (2009). Análise de conteúdo (L. A. Reto \& A. Pinheiro, Trads.). Lisboa, Portugal: Edições 70. (Original publicado em 1977)

Bauer, M., \& Jovchelovitch, S. (1999). A questão da metodologia em pesquisa: Texto, imagem e materiais sonoros. Manuscrito não publicado, Curso de Extensão, Pós-Graduação em Psicologia, Pontifícia Universidade Católica do Rio Grande do Sul, Porto Alegre, RS, Brasil.
Bosinski, H. A. (2006). [Psychosexual aspects of intersex syndromes]. Der Urologe, 45(8), 981-991.

Damiani, D., \& Steinmetz, L. (2010). Critérios diagnósticos. In A. T. Maciel-Guerra \& G. Guerra-Júnior (Eds.), Menino ou menina? distúrbios da diferenciação do sexo (pp. 75-78). Rio de Janeiro, RJ: Rubio.

Freud, S. (1996a). Algumas consequências psíquicas da distinção anatômica entre os sexos (M. A. M. Rego, Trad.). In J. Salomão (Ed.), Edição standard brasileira de obras completas de Sigmund Freud (Vol. 19, pp. 273-286). Rio de Janeiro, RJ: Imago. (Original publicado em 1925)

Freud, S. (1996b). Três ensaios sobre a teoria da sexualidade (M. A. M. Rego, Trad.). In J. Salomão (Ed.), Edição standard brasileira de obras completas de Sigmund Freud (Vol. 7, pp. 119-209). Rio de Janeiro, RJ: Imago. (Original publicado em 1905)

Kleinemeier, E., Jürgensen, M., Lux, A., Widenka, P. M., \& Thyen, U. (2010). Psychological adjustment and sexual development of adolescents with disorders of sex development. Journal of Adolescent Health, 47, 463-471.

Money, J., \& Ehrhardt, A. (1972). Man \& woman, boy \& girl. Baltimore, MD: The Johns Hopkins University Press.

Money, J., Hampson, J., \& Hampson, J. (1957). Imprinting and establishment of gender role. Archives of Neurology and Psychiatry, 77, 333-336.

Nihoul-Fékété, C. (2008). How to deal with congenital disorders of sex development in 2008 (DSD). European Journal of Pediatric Surgery, 18(6), 364-367.

Santos, M. M. R., \& Araujo, T. C. C. F. (2003). A clínica da intersexualidade e seus desafios para os profissionais de saúde. Psicologia: Ciência e Profissão, 23(3), 26-33.

Santos, M. M. R., \& Araujo, T. C. C. F. (2004). Intersexo: O desafio da construção da identidade de gênero. Revista da Sociedade Brasileira de Psicologia Hospitalar, 7(1), 17-28.

Slijper, F. M. E., van der Kamp, H. J., Brandenburg, H., de Muinck Keizer-Shrama, S. M. P. F., Drop, S. L. S., \& Molenaar, J. C. (1992). Evaluation of psychosexual development of young womem with congenital adrenal hyperplasia: A pilot study. Journal of Sex Education \& Therapy, 18, 200-207.

Spinola-Castro, A. M. (2010). Aspectos históricos e éticos dos distúrbios da diferenciação do sexo. In A. T. Maciel-Guerra \& G. Guerra-Júnior (Eds.), Menino ou menina? Distúrbios da diferenciação do sexo (pp. 455-477). Rio de Janeiro, RJ: Rubio.

Stoller, R. (1993). Masculinidade e Feminilidade: Apresentações do gênero (M. A. V. Veronese, Trad.). Porto Alegre, RS: Artes Médicas.

Telles-Silveira, M., Tonetto-Fernandes, V., Schiller, P., \& Kater, C. (2009). Hiperplasia Adrenal Congênita: Estudo qualitativo sobre a definição e redefinição sexual, cirurgia de dilatação e apoio psicológico (parte II). Arquivos Brasileiros de Endocrinologia e Metabologia, 53(9), 1125-1136.

Zucker, K. J. (2006). Gender identity and intersexuality. In S. E. Sytsma (Ed.), Ethics and Intersex (pp. 165-181). Dordrecht, Netherlands: Springer. 